\title{
Elevated lactate in acute heart failure patients with intracellular iron deficiency as an identifier of poor outcome
}

\author{
Jan Biegus ${ }^{1,2}$, Robert Zymliński ${ }^{1,2}$, Mateusz Sokolski ${ }^{1,2}$, Ewa A. Jankowska ${ }^{1,2}$, \\ Waldemar Banasiak ${ }^{2}$, Piotr Ponikowski ${ }^{1,2}$ \\ 'Department of Heart Diseases, Wroclaw Medical University, Wroclaw, Poland \\ ${ }^{2}$ Centre for Heart Diseases, $4^{\text {th }}$ Military Hospital, Wroclaw, Poland
}

\begin{abstract}
A b stract
Background: We believe that there is a physiological link between intracellular iron status (assessed by soluble transferrin receptor [sTfR]) and efficiency of energy production/consumption (assessed by lactate, a product of anaerobic cell metabolism), which may further impact the outcome of patients with acute heart failure (AHF).

Aim: To examine if elevated levels of lactate ( $>2 \mathrm{mmol} / \mathrm{L}$ ) accompanied by unmet cellular iron requirements (defined as sTfR $>1.59 \mathrm{mg} / \mathrm{L}$ ) identify AHF patients with an unfavourable outcome.

Methods: The study is a single-centre, retrospective analysis of AHF patients in whom lactate and iron status were assessed on admission. The endpoint of the study was one-year mortality.

Results: The study population consisted of 89 patients at a mean age of $65 \pm 13$ years. Mean systolic blood pressure and creatinine level were $135 \pm 36 \mathrm{mmHg}$ and $1.3 \pm 0.6 \mathrm{mg} / \mathrm{dL}$, respectively, and median $\left[25^{\text {th }}-75^{\text {th }}\right.$ quartiles] lactate level on admission was 2.0 [1.6-2.6] mmol/L. In 17 (19\%) patients, both lactate and sTfR were below the cut-off values (group 1). In $38(43 \%)$ individuals one of the markers was elevated (group 2) and in the remaining 34 (38\%) patients both markers were above the predefined cut-off values (group 3). There was no difference in clinical and laboratory characteristics between the groups. During one-year follow-up $23(26 \%)$ patients died. Mortality risk in group 3 was higher compared to the rest of the population (hazard ratio 5.6,95\% confidence interval $2.2-14, p=0.0003$ ), even after adjustments for well-defined prognostic factors.

Conclusions: Patients with unmet iron cell requirements and hyperlactataemia on admission have significantly higher mortality risk compared to individuals without those pathologies.
\end{abstract}

Key words: acute heart failure, iron deficiency, lactate, metabolism

Kardiol Pol 2019; 77, 3: 347-354

\section{INTRODUCTION}

Acute heart failure (AHF) is a syndrome with complex pathophysiology and it should not be simplified only to congestion and inadequate cardiac output [1, 2]. We believe that during every AHF episode the patient is exposed to metabolic stress driven by neurohormonal and adrenergic activation, which may lead to organ dysfunction [3-8]. Patients unable to cope with the stress may have a worse outcome.

In the traditional approach, lactate is believed to be an end-product of anaerobic cell metabolism, which occurs during oxidative stress $[9,10]$. This marker is continuously produced and cleared to maintain its physiological concentration [11]. Compromised adaptation reflected by the inability to maintain the balance between lactate production and elimination results in its systemic accumulation [10, 11]. Inadequate peripheral perfusion, low cardiac output, activation of sympathetic drive, vasoconstriction, organ dysfunction, as well as anaemia and iron deficiency can all conspire to promote energetic/metabolic oppression in AHF, which may further manifest as hyperlactataemia [10-12]. Only recently

\section{Address for correspondence:}

Jan Biegus, MD, Department of Heart Diseases, Wroclaw Medical University, Centre for Heart Diseases, Military Teaching Hospital, ul. Weigla 5, 53-114 Wrocław, Poland, tel: +48 7176602 37, fax: +48 7176602 28, e-mail: janbiegus@gmail.com

Received: 15.12.2018 Accepted: 17.01.2019 Available as AoP: 18.01.2019 
has the prognostic significance of lactate acid in heart failure (HF) been shown $[8,13,14]$.

Iron is a vital cofactor and catalyst of enzymes that regulate cell energy production [15]. It is also a key micronutrient crucial for erythropoiesis, oxygen transport, and tissue oxygenation [15]. Thus, iron deficiency may lead to the dysregulation of several mechanisms that buffer cell energetics and therefore promote the anaerobic (less efficient) pathway of energy supply. There are several biomarkers reflecting different iron statuses, such as serum iron, transferrin saturation (TSAT), and serum ferritin. Unfortunately, those variables are affected by many external factors and therefore seem to be unreliable in the AHF setting [15]. Soluble transferrin receptor (sTfR) is a transmembrane cell receptor that is shed from cells to incorporate iron into the cells. Therefore, elevated STfR is a marker reflecting unmet intracellular iron requirements.

There should be a strong pathophysiological link between cellular iron status and the efficiency of energy production and, consequently, the ability to adapt to the stress related to an AHF event. Although there are reasons to believe that both iron deficiency and elevated lactate (separately) have prognostic significance in $\mathrm{HF}$, there are no data on their coexistence and its clinical consequences in $\mathrm{AHF}[8,16]$.

We aimed to examine if elevated lactate levels ( $>2 \mathrm{mmol} / \mathrm{L}$ ) accompanied by unmet cellular iron requirements (defined as sTfR elevation $>1.59 \mathrm{mg} / \mathrm{L}$ ) on admission identify patients with an unfavourable outcome.

\section{METHODS}

The study population consisted of patients hospitalised at the Centre for Heart Diseases, $4^{\text {th }}$ Military Hospital, Wroclaw, Poland, between 2010 and 2012 [16] with primary diagnosis of AHF, in whom sTfR and lactate levels could be assessed. Patients with known liver disease, on dialysis, with any treatment for anaemia as well as those with clinical diagnosis of acute coronary syndrome or cardiogenic shock were excluded. After enrolment, information on demographics, clinical history, comorbidities, previous therapies, and physical examination findings was recorded. Lactate levels were assessed on admission as part of a standard capillary blood gas test.

\section{Laboratory measurements}

On admission, the following laboratory measurements were taken using standard methods (blood samples were drawn at the Emergency Department or within the first hour of hospitalisation as part of standard AHF patient care):

- capillary blood for oxygen saturation (\%), carbon dioxide concentration $(\mathrm{mmHg}), \mathrm{pH}$, bicarbonate $(\mathrm{mmol} / \mathrm{L})$, and lactate (mmol/L); direct method, ABL 800 Flex analyser, (Radiometer, Copenhagen, Denmark);

- haematology: haemoglobin ( $\mathrm{g} / \mathrm{dL}$; conversion factor to SI units: $10[\mathrm{~g} / \mathrm{L}])$, white blood cell count $(\mathrm{G} / \mathrm{L}$; conversion factor to SI units: 1$)$, platelet count $(\mathrm{G} / \mathrm{L}$; conversion factor to SI units: 1);
— serum electrolytes: sodium $\left(\mathrm{Na}^{+}, \mathrm{mmol} / \mathrm{L}\right)$;

- renal test: creatinine $(\mathrm{mg} / \mathrm{dL}$; conversion factor to $\mathrm{SI}$ units: $88.4[\mu \mathrm{mol} / \mathrm{L}])$; estimated glomerular filtration rate (eGFR) calculated by the Modification of Diet in Renal Disease (MDRD) formula: eGFR $=175 \times$ serum $\mathrm{Cr}^{-1.154} \times$ $\times$ age $^{-0.203} \times 1.212$ (if patient is black) $\times 0.742$ (if female); serum creatinine in $\mathrm{mg} / \mathrm{dL}$ was used for this formula;

- liver function tests: aspartate aminotransferase (AST, $\mathrm{IU} / \mathrm{L})$, alanine aminotransferase (IU/L), bilirubin $(\mathrm{mg} / \mathrm{dL}$; conversion factor to SI units: $17.1[\mu \mathrm{mol} / \mathrm{L}])$;

- plasma N-terminal pro-B-type natriuretic peptide (NT-proBNP); immunoenzymatic assay (Siemens, Marburg, Germany).

The following measurements of iron status were performed:

- serum ferritin ( $\mathrm{mg} / \mathrm{L}$ ) measured using an immunoassay based on electrochemiluminescence with the Elecsys 2010 System (Roche Diagnostics $\mathrm{GmbH}$, Mannheim, Germany);

- serum iron $(\mathrm{mg} / \mathrm{dL})$ and total iron-binding capacity (TIBC, $\mathrm{mg} / \mathrm{dL}$ ) assessed using a substrate method with Feren $\mathrm{S}$ (Thermo Fisher Scientific, Waltham, MA, USA);

- serum sTfR $(\mathrm{mg} / \mathrm{L})$ measured from plasma frozen at $-70^{\circ} \mathrm{C}$ using immunonephelometry (Siemens Healthcare Diagnostics, Inc., Deerfield, IL, USA);

- serum hepcidin $(\mathrm{ng} / \mathrm{mL})$ was measured from plasma frozen at $-70^{\circ} \mathrm{C}$ using a commercially available enzyme-linked immunosorbent assay (ELISA) (BACHEM) (Cat. No. S-1337 detecting human hepcidin-25). The ELISA method was validated with liquid chromatography mass spectrometry, the gold standard for hepcidin assessment.

Transferrin saturation was calculated as the ratio of serum iron $(\mathrm{mg} / \mathrm{dL})$ and TIBC (mg/dL) multiplied by 100 and expressed as a percentage. In accordance with previous reports, iron deficiency was defined as serum ferritin $<100 \mu \mathrm{g} / \mathrm{L}$ or serum ferritin 100-299 $\mu \mathrm{g} / \mathrm{L}$ and TSAT $<20 \%$.

During hospitalisation every patient underwent standard clinical evaluation and received guideline-recommended treatment $[17,18]$.

The study protocol was approved by the Local Ethics Committee, and the study was conducted in compliance with the Helsinki Declaration.

\section{Patient groups}

According to recent papers and guidelines, we set arbitrary cut-off values: for lactate at $2 \mathrm{mmol} / \mathrm{L}$ and for sTfR at $1.59 \mathrm{mg} / \mathrm{L}$ $\left(95^{\text {th }}\right.$ percentile in healthy peers) $[8,15,16,19]$. On this basis, patients were divided into three groups:

- group 1: patients with both markers below the cut-off values;

- group 2: individuals with separate elevation of either lactates or sTfR;

- group 3: patients with both values above the predefined cut-off values. 


\section{Statistical analysis}

The end-point of the study was all-cause death at one-year follow-up. Continuous variables with a normal distribution were described using means \pm standard deviation, variables with skewed distribution were described by medians with upper and lower quartiles, and categorical variables were provided as numbers and percentages. The variables with skewed distribution were log-transformed where appropriate. The comparison between groups with different sTfR and lactate profiles was made using the analysis of variance (Kruskal-Wallis test) and the $\chi^{2}$ test where appropriate. The Cox proportional hazards model was used to calculate the hazard ratio $(\mathrm{HR})$ with the corresponding 95\% confidence interval $(\mathrm{Cl})$ for all-cause mortality. Afterwards, the HR was adjusted for systolic blood pressure, serum sodium, or creatinine (each adjustment was made separately due to a low number of events). Kaplan-Meier curves for cumulative survival were constructed. A value of $p<0.05$ was considered statistically significant. Statistical analyses were performed using the STATISTICA 13 data analysis software system (StatSoft, Inc., Tulsa, OK, USA).

\section{RESULTS \\ Characteristics}

The study population consisted of $89 \mathrm{AHF}$ patients at a mean age of $65 \pm 13$ years, including 64 (72\%) men, with predominant ischaemic HF aetiology (47 cases, 53\%). There were $24(27 \%)$ patients with de novo AHF, the remaining 65 patients had decompensation of chronic HF. The mean base characteristics on admission were as follows: ejection fraction (EF): 32\% $\pm 13 \%$, heart rate: $92 \pm 26 \mathrm{bpm}$, systolic blood pressure: $135 \pm 36 \mathrm{mmHg}$, creatinine: $1.3 \pm 0.6 \mathrm{mg} / \mathrm{dL}$, and haemoglobin: $13.3 \pm 1.8 \mathrm{~g} / \mathrm{dL}$. The median $\left(25^{\text {th }}-75^{\text {th }}\right.$ quartiles) NT-proBNP and lactate levels on admission were: 7550 (2928-8775) pg/mL and 2.0 (1.6-2.6) mmol/L, respectively. The detailed characteristics of the study population are shown in Table 1.

The mean values of iron status markers were: serum iron: 61 (48-87) $\mu \mathrm{g} / \mathrm{dL}$, TSAT: $17.8 \%$ (13.9\%-25\%), ferritin: 92.4 (62.5-153.2) $\mu \mathrm{g} / \mathrm{L}$, and sTfR: 1.9 (1.5-2.7) mg/L (Table 1).

\section{Comparison of patients with different sTfR/lactate profiles}

Only 17 (19\%) patients had both lactate and sTfR levels below the cut-off values (group 1). In total, 38 (43\%) individuals had separate elevation of either lactates (nine patients) or sTfR (29 patients) on admission (group 2). In the remaining $34(38 \%)$ patients, both markers were above the predefined cut-off values (group 3). There was no difference in basic clinical variables between patients with different lactate and sTfR profiles (Table 2). Patients in whom both biomarkers were elevated had higher values on liver function tests (AST: 29 [26-40] IU/L and bilirubin: 1.1 [0.8-2.4] mg/dL) on admission compared to the other groups $(p<0.05)$. Apart from that,
Table 1. Baseline characteristics of patients with acute heart failure

\section{Parameter}

Population $(n=89)$

Male sex

Age [years]

Heart rate $[\mathrm{bpm}]$

SBP on admission [mmHg]

Left ventricular ejection fraction [\%]

Acute heart failure (de novo)

Heart failure aetiology:

Ischaemic

Hypertension

Valve disease

Comorbidities:

Previous MI

Hypertension

$64(72)$

$65 \pm 13$

$92 \pm 26$

$135 \pm 36$

$32 \pm 13$

24 (27)

Atrial fibrillation

$43(48)$

7 (8)

$18(20)$

Diabetes mellitus

33 (37)

59 (66)

$52(58)$

34 (38)

Liver function tests:

AST [IU/L]

26 [20-36]

ALT [IU/L]

26 [17-37]

Bilirubin [mg/dL]

$1.1[0.8-1.6]$

Blood count:

Haemoglobin [g/dL]

White blood cell count $[\mathrm{G} / \mathrm{L}]$

Platelet count $[\mathrm{G} / \mathrm{L}]$

Serum sodium $[\mathrm{mmol} / \mathrm{L}]$

Creatinine $[\mathrm{mg} / \mathrm{dL}]$

CRP [mg/L]

NT-proBNP [pg/mL]

Troponin I [ng/mL]

Iron biomarkers:

Serum iron $[\mu \mathrm{g} / \mathrm{dL}]$

TIBC $[\mu \mathrm{g} / \mathrm{dL}]$

TSAT [\%]

Ferritin $[\mu \mathrm{g} / \mathrm{L}]$

sTfR [mg/L]

Iron deficiency*

Hepcidin [ng/mL]

$13.3 \pm 1.8$

$9 \pm 3.8$

$221 \pm 99$

$138 \pm 5$

$1.3 \pm 0.6$

7.2 [3.0-19]

7550 [2928-8775]

$0[0-0.1]$

61 [48-87]

352 [305-389]

17.8 [13.9-25]

$92.4[62.5-153.2]$

$1.9[1.5-2.7]$

$66(74)$

$12.9[3.1-34.2]$

Peripheral blood gas test:

$\mathrm{pH}$

$\mathrm{sO}_{2}[\%]$

$\mathrm{pCO}_{2}[\mathrm{mmHg}]$

$\mathrm{HCO}_{3}^{-}[\mathrm{mmol} / \mathrm{L}]$

Lactate $[\mathrm{mmol} / \mathrm{L}]$

In-hospital:

SBP at $48 \mathrm{~h}$ [mmHg]

Creatinine at $48 \mathrm{~h}[\mathrm{mg} / \mathrm{dL}]$

Length of hospitalisation [days]

Dyspnoea on admission (0-10 scale)

Dyspnoea at $48 \mathrm{~h}$ (0-10 scale)

Inotrope use

$7.4 \pm 0.1$

$91 \pm 9$

$39 \pm 13$

$24 \pm 4$

$2.0[1.6-2.6]$

$115 \pm 18$

$1.2 \pm 0.6$

$10 \pm 8.9$

$7.5 \pm 1.9$

$2.2 \pm 2.4$

$6(7)$

$95 \pm 61$

Dose of furosemide (IV) 0-4 h [mg]

Dose of furosemide (IV) 24-48 h [mg]

$44 \pm 51$

Data are shown as number (percentage), mean \pm standard deviation or median $\left[25^{\text {th }}-75^{\text {th }}\right.$ quartiles]. ALT - alanine aminotransferase; AST - aspartate aminotransferase; CRP — C-reactive protein: $\mathrm{HCO}_{3}{ }^{-}$- bicarbonate; $\mathrm{Ml}$ - myocardial infarction; NT-proBNP $\mathrm{N}$-terminal pro-B-type natriuretic peptide; $\mathrm{pCO}_{2}-$ partial pressure of carbon dioxide; $\mathrm{SBP}$ - systolic blood pressure; $\mathrm{sO}_{2}$ - oxygen saturation; STfR — soluble transferrin receptor; TIBC — total iron-binding capacity, TSAT — transferrin saturation

*Defined by serum ferritin and TSAT (serum ferritin $<100 \mu \mathrm{g} / \mathrm{L}$,

or serum ferritin 100-299 $\mu \mathrm{g} / \mathrm{L}$ and TSAT $<20 \%$ ) 
Table 2. Comparison of patients with different soluble transferrin receptor (sTfR) and lactate profiles

\begin{tabular}{|c|c|c|c|c|}
\hline Parameter & $\begin{array}{l}\text { Group 1: patients } \\
\text { with normal sTfR } \\
\text { and lactate levels } \\
\qquad(n=17)\end{array}$ & $\begin{array}{l}\text { Group 2: patients with } \\
\text { abnormal level of } \\
\text { either sTfR or lactate } \\
\qquad(n=38)\end{array}$ & $\begin{array}{l}\text { Group 3: patients } \\
\text { with abnormal } \\
\text { levels of both sTfR } \\
\text { and lactate }(n=34)\end{array}$ & $\mathbf{p}$ \\
\hline Male sex & $10(59)$ & $29(76)$ & $25(74)$ & 0.39 \\
\hline Age [years] & $64 \pm 14$ & $66 \pm 13$ & $65 \pm 13$ & 0.9 \\
\hline Heart rate $[\mathrm{bpm}]$ & $85 \pm 27$ & $93 \pm 27$ & $94 \pm 25$ & 0.2 \\
\hline SBP on admission $[\mathrm{mmHg}]$ & $140 \pm 33$ & $134 \pm 32$ & $134 \pm 41$ & 0.7 \\
\hline Left ventricular ejection fraction [\%] & $32 \pm 13$ & $32 \pm 14$ & $31 \pm 12$ & 0.7 \\
\hline Acute heart failure (de novo) & $12(71)$ & $25(66)$ & $28(82)$ & 0.27 \\
\hline \multicolumn{5}{|l|}{ Heart failure aetiology: } \\
\hline Ischaemic & $8(47)$ & $18(47)$ & $17(50)$ & 0.95 \\
\hline Hypertension & $1(6)$ & $4(11)$ & $2(6)$ & \\
\hline Valve disease & $4(24)$ & $6(16)$ & $8(24)$ & \\
\hline \multicolumn{5}{|l|}{ Comorbidities: } \\
\hline Previous MI & $5(29)$ & $13(34)$ & $15(44)$ & 0.52 \\
\hline Hypertension & $12(71)$ & $26(68)$ & $21(62)$ & 0.76 \\
\hline Atrial fibrillation & $10(59)$ & $25(66)$ & $17(50)$ & 0.39 \\
\hline Diabetes mellitus & $3(18)$ & $14(37)$ & $17(50)$ & 0.07 \\
\hline \multicolumn{5}{|l|}{ Liver function tests: } \\
\hline AST [IU/L] & $22[21-36]$ & $23[18-26]^{\mathrm{b}}$ & $29[26-40]$ & 0.01 \\
\hline ALT $[I U / L]$ & $25[17-36]$ & $26[16-35]$ & $26[19-42]$ & 0.6 \\
\hline Bilirubin [mg/dL] & $0.8[0.6-1.1]$ & $1.1[0.8-1.6]$ & $1.1[0.8-2.4]^{\mathrm{ccc}}$ & 0.01 \\
\hline \multicolumn{5}{|l|}{ Blood count: } \\
\hline Haemoglobin $[\mathrm{g} / \mathrm{dL}]$ & $13.1 \pm 2$ & $13.8 \pm 1.7$ & $13.3 \pm 1.7$ & 0.25 \\
\hline White blood cell count [G/L] & $9.4 \pm 3.2$ & $8.3 \pm 3.2$ & $9.7 \pm 4.4$ & 0.4 \\
\hline Platelet count $[\mathrm{G} / \mathrm{L}]$ & $224 \pm 74$ & $228 \pm 120$ & $214 \pm 86$ & 0.81 \\
\hline Serum sodium [mmol/L] & $138 \pm 7$ & $138 \pm 3$ & $138 \pm 5$ & 0.6 \\
\hline Creatinine $[\mathrm{mg} / \mathrm{dL}]$ & $1.1 \pm 0.2$ & $1.3 \pm 0.6$ & $1.4 \pm 0.8$ & 0.25 \\
\hline $\mathrm{CRP}[\mathrm{ml} / \mathrm{L}]$ & $6.1[2.1-14]$ & $5.6[3-14]$ & $9.5[4-20]$ & 0.51 \\
\hline NT-proBNP [pg/mL] & $4351[2674-7910]$ & $6037[2502-9111]$ & $6396[3784-8287]$ & 0.54 \\
\hline Troponin I [ng/mL] & $0[0-0.1]$ & $0.1[0-0.1]$ & $0[0-0.1]$ & 0.29 \\
\hline \multicolumn{5}{|l|}{ Iron biomarkers: } \\
\hline Serum iron $[\mu \mathrm{g} / \mathrm{dL}]$ & 73 [54-96] & $60[47-74]$ & 62 [47-90] & 0.45 \\
\hline $\operatorname{TIBC}[\mu \mathrm{g} / \mathrm{dL}]$ & $342[287-380]$ & 363.5 [319-397] & 349 [298-387] & 0.35 \\
\hline TSAT [\%] & $23.9[14.7-30.0]$ & $17.6[12.9-20.7]$ & $17.8[15-26]$ & 0.15 \\
\hline Ferritin $[\mu \mathrm{g} / \mathrm{L}]$ & $90.6[71.1-198.2]$ & $85.7[65-149.7]$ & $98[59.9-152.2]$ & 0.93 \\
\hline $\mathrm{sTfR}[\mathrm{mg} / \mathrm{L}]$ & $1.4[1.2-1.5]^{\text {aa }}$ & $1.9[1.6-2.5]^{\mathrm{bbb}}$ & $2.5[1.8-3.7]^{\mathrm{ccc}}$ & $<0.001$ \\
\hline Iron deficiency* & $11(64)$ & $30(79)$ & $25(76)$ & 0.5 \\
\hline Hepcidin $[\mathrm{ng} / \mathrm{mL}]$ & $26.4[17-60]$ & $7.9[2.7-30]$ & $7.2[2.6-27]$ & \\
\hline \multicolumn{5}{|l|}{ Peripheral blood gas test: } \\
\hline $\mathrm{pH}$ & $7.4 \pm 0.1$ & $7.4 \pm 0.1$ & $7.4 \pm 0.1$ & 0.32 \\
\hline $\mathrm{SO}_{2}[\%]$ & $91 \pm 9$ & $94 \pm 4$ & $89 \pm 12$ & 0.48 \\
\hline $\mathrm{pCO}_{2}[\mathrm{mmHg}]$ & $42 \pm 18$ & $39 \pm 11$ & $38 \pm 11$ & 0.59 \\
\hline $\mathrm{HCO}_{3}^{-}[\mathrm{mmol} / \mathrm{L}]$ & $26 \pm 3$ & $25 \pm 4$ & $23 \pm 3^{c}$ & 0.01 \\
\hline Lactate $[\mathrm{mmol} / \mathrm{L}]$ & $1.6[1.6-1.9]$ & $1.6[1.4-2.0]^{\mathrm{bbb}}$ & $2.7[2.3-3.3]^{\mathrm{ccc}}$ & $<0.001$ \\
\hline \multicolumn{5}{|l|}{ In-hospital: } \\
\hline $\mathrm{SBP}$ at $48 \mathrm{~h}[\mathrm{mmHg}]$ & $119 \pm 4.5$ & $114.5 \pm 2.9$ & $115 \pm 3.2$ & 0.74 \\
\hline Creatinine at $48 \mathrm{~h}[\mathrm{mg} / \mathrm{dL}]$ & $0.99 \pm 0.2$ & $1.29 \pm 0.1$ & $1.22 \pm 0.1$ & 0.27 \\
\hline Length of Hospitalisation [days] & $8.2 \pm 5$ & $8.9 \pm 5$ & $12.8 \pm 12$ & 0.1 \\
\hline Dyspnoea on admission (scale of 0-10) & $7.0 \pm 2.5$ & $7.3 \pm 1.8$ & $8.0 \pm 1.8$ & 0.36 \\
\hline Dyspnoea at $48 \mathrm{~h}$ (0-10 scale) & $2.9 \pm 1.6$ & $2.5 \pm 1.9$ & $3.1 \pm 2.3$ & 0.41 \\
\hline Inotrope use & $0(0)$ & $1(3)$ & $5(15)^{c}$ & 0.058 \\
\hline Dose of furosemide (IV) 0-24 h [mg] & $91 \pm 49$ & $98 \pm 66$ & $94 \pm 64$ & 0.9 \\
\hline Dose of furosemide (IV) 24-48 h [mg] & $29 \pm 38$ & $35 \pm 51$ & $62 \pm 55$ & 0.035 \\
\hline
\end{tabular}

Data are shown as number (percentage), mean \pm standard deviation or median $\left[25^{\text {th }}-75^{\text {th }}\right.$ quartiles]. Abbreviations - see Table 1

$a / b / c p<0.05 ;$ aa/bb/c $p<0.01$; aa//bbb/ccc $p<0.001 ; a$ - comparison between group 1 and $2 ; b$ - comparison between group 2 and 3; $c$ - comparison between group 1 and 3

*Defined by serum ferritin and TSAT (serum ferritin < $100 \mu \mathrm{g} / \mathrm{L}$, or serum ferritin 100-299 $\mu \mathrm{g} / \mathrm{L}$ and TSAT $<20 \%$ ) 
Table 3. Predictors of one-year mortality: univariate and multivariate analyses

\begin{tabular}{|c|c|c|}
\hline Variable & HR $(95 \% \mathrm{Cl})$ & p \\
\hline \multicolumn{3}{|l|}{ Univariate analyses: } \\
\hline SBP (per $1 \mathrm{mmHg}$ ) & $0.9[0.9-1.0]$ & 0.08 \\
\hline Serum sodium (per 1 mmol/L) & $0.9[0.8-0.9]$ & $<0.0005$ \\
\hline Creatinine (per 1 mg/dL) & $2.3[1.5-3.6]$ & 0.0004 \\
\hline eGFR (per $1 \mathrm{~mL} / \mathrm{min}$ ) & $0.9[0.9-0.9]$ & 0.001 \\
\hline Haemoglobin (per $1 \mathrm{~g} / \mathrm{dL}$ ) & $0.8[0.6-0.9]$ & $<0.05$ \\
\hline NT-proBNP ${ }_{\log }($ per pg/mL) & $2.3[1.4-3.9]$ & 0.002 \\
\hline $\mathrm{sTfR}>1.59 \mathrm{mg} / \mathrm{L}$ & $4.9[1.1-20.9]$ & 0.03 \\
\hline Lactate $>2 \mathrm{mmol} / \mathrm{L}$ & $3.4[1.3-8.7]$ & 0.009 \\
\hline sTfR $>1.59 \mathrm{mg} / \mathrm{L}$ and lactate $>1.59 \mathrm{mg} / \mathrm{L}$ & $5.6[2.2-14.3]$ & 0.0003 \\
\hline \multicolumn{3}{|l|}{ Multivariate analyses: } \\
\hline $\mathrm{sTfR}>1.59 \mathrm{mg} / \mathrm{L}$ and lactate $>1.59 \mathrm{mg} / \mathrm{L}$ (yes) ${ }^{*}$ & $5.4[2.1-13.7]$ & 0.0005 \\
\hline sTfR $>1.59 \mathrm{mg} / \mathrm{L}$ and lactate $>1.59 \mathrm{mg} / \mathrm{L}$ (yes) ${ }^{* *}$ & $5.5[2.1-14.0]$ & 0.0005 \\
\hline $\mathrm{sTfR}>1.59 \mathrm{mg} / \mathrm{L}$ and lactate $>1.59 \mathrm{mg} / \mathrm{L}$ (yes) ${ }^{* * *}$ & $5.5[2.2-14.2]$ & 0.0003 \\
\hline $\mathrm{sTfR}>1.59 \mathrm{mg} / \mathrm{L}$ and lactate $>1.59 \mathrm{mg} / \mathrm{L}$ (yes) ${ }^{* * * *}$ & $6.2[2.4-16.4]$ & 0.0002 \\
\hline
\end{tabular}

*Adjusted for serum sodium; **Adjusted for creatinine; ${ }^{* * *}$ Adjusted for estimated glomerular filtration rate (eGFR); ****Adjusted for NT-proBNP eGFR assessed by the Modification of Diet in Renal Disease (MDRD) formula: eGFR $=175 \times$ serum $\mathrm{Cr}^{-1.154} \times$ age $^{-0.203} \times 1.212$ (if patient is black) $\times 0.742$ (if female). Serum creatinine in $\mathrm{mg} / \mathrm{dL}$ was used for this formula. Abbreviations — see Table 1

we found no difference between the three groups in most of the laboratory variables, such as blood count, $\mathrm{Na}^{+}$, creatinine, NT-proBNP, troponin, C-reactive protein, $\mathrm{pH}$, and saturation (Table 2). Moreover, the comparison of iron status (assessed by serum iron, TIBC, ferritin, and TSAT) between the groups did not reveal any differences (Table 2).

\section{Predictive value}

During one-year follow-up 23 (26\%) patients died. Univariate models confirmed that well-established risk factors, such as serum sodium (HR 0.9, 95\% Cl 0.8-0.9, p < 0.05), creatinine (HR 2.3, 95\% Cl 1.5-3.6, p < 0.05), and NT-proBNP ${ }_{(\log )}$ (HR 2.3, 95\% Cl 1.4-3.9, p < 0.05) had predictive values in our cohort. Moreover, separate elevation of either marker also had significant prognostic importance (HR 3.4, 95\% Cl 1.3-8.7, p < 0.05 for lactate and HR 4.9, 95\% Cl 1.1-20.9, $\mathrm{p}<0.05$ for sTfR) (Table 3 ).

Patients with coexisting elevated levels of lactate and sTfR had a significantly higher mortality rate than groups 1 and 2: $50 \%$ vs. $11.7 \%$ and $10.5 \%$, respectively (log rank $p<0.001)$ (Fig. 1). Thus, group 3 had significantly higher mortality risk when compared to the rest of the population (HR 5.6, 95\% CI $2.2-14, p=0.0003)$, which remained significant even after adjustments for each of the following: sodium, creatinine, NT-proBNP, or eGFR (Table 3).

\section{DISCUSSION}

To the best of our knowledge, this is the first report showing that patients with unmet iron cell requirements (defined as

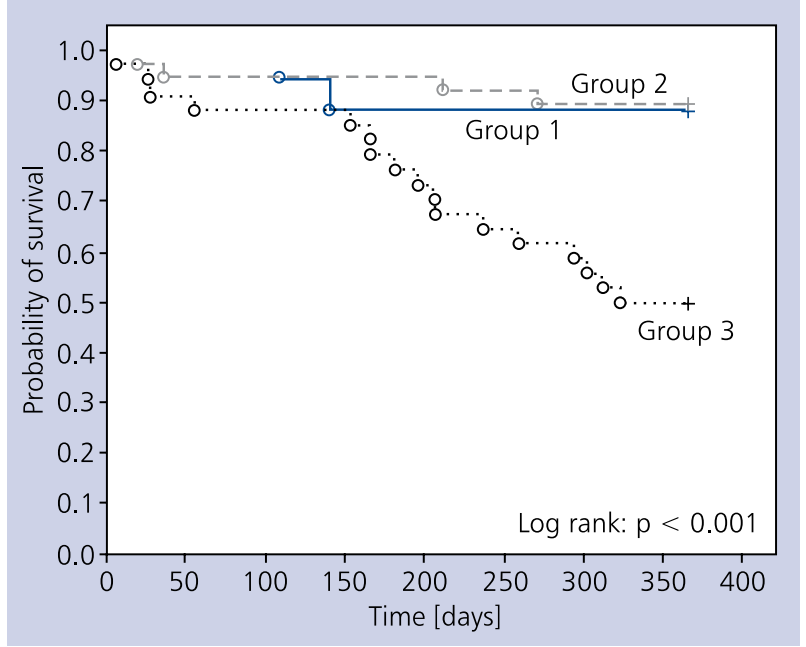

Figure 1. Kaplan-Meier curves. Probability of survival in patients with different lactate and soluble transferrin receptor (sTfR) profiles ( $n=89$ ); Group 1 - patients with both markers (lactate and STfR) below cut-off values; Group 2 - patients with elevation of either lactate or sTfR levels; Group 3 - patients with both markers above the predefined cut-off values

sTfR > $1.59 \mathrm{mg} / \mathrm{L})$ who also demonstrate elevated lactate levels on admission have significantly higher mortality risk when compared to individuals without these pathologies. The detailed mechanisms of that phenomenon remain unknown; however, we may speculate that there should be a pathophysi- 
ological link between intracellular iron status, the ability to produce (and consume) energy, and mortality in AHF. The aforementioned mechanism is definitely complex and much more sophisticated than just "simple" iron deficiency-driven anaemia or hypoxia because we found no differences in haemoglobin values and oxygen saturation across the three groups. Moreover, we have recently reported that lactate is not correlated with respiratory disturbances in the broad spectrum of HF patients [20]. We believe that the coexistence of these two factors is not accidental and may actually identify patients with functional intracellular iron insufficiency that leads to energy debt with its clinical consequences.

The pathophysiology of lactate accumulation in AHF is definitely complex. As already mentioned, there are several mechanisms that may conspire in promotion of hyperlactataemia in AHF [8, 21]. Recently, new insights into pathophysiology of hyperlactataemia have been revealed, which can change our understanding of this phenomenon [22]. Accumulation of lactate during stress may actually be a result of its aerobic (not anaerobic) production, which is controlled by the adrenergic system [22]. Hyperlactataemia may be an adaptation to stress related to increased energetic demand and sympathetic nervous system activation, which lead to accelerated glycolysis [22]. Lactate itself may be a source of energy for some cells, thus it may have protective capabilities [22-25]. In fact, our previous observations seem to confirm that assumption, as in HF patients; adrenergic drive (represented by heart rate), tissue hypoperfusion (expressed as systemic vascular resistance), and depressed lactate clearance (liver dysfunction) were strongly correlated with lactate $[8,20]$. There was no evidence to link lactate with hypoxia and hypoxaemia in our HF population [20]. Moreover, there are grounds to believe that lactate may facilitate modification of protein expression that leads to more efficient energy consumption [22]. It is worth noting that, irrespective of its pathophysiological background, hyperlactataemia remains a marker of energetic stress.

The three groups were virtually the same in the context of well-established AHF prognostic factors, such as systolic blood pressure, serum sodium, creatinine, NT-proBNP, or troponin level on admission [26-28]. This observation may suggest that the prognostic importance of coexisting elevation of lactate and sTfR levels was irrespective of these vital variables. Multivariable analyses were not possible to perform due to the low number of events during follow-up, however, an adjustment for one of the following: natriuretic peptide, serum sodium, creatinine, or eGFR confirmed that assumption. It is also worth noting that almost three-fourths of all deaths (17 out of 23) occurred in patients with high levels of lactate and STfR, which confirms their strong prognostic significance.

Moreover, the groups did not differ in markers commonly used for iron status assessment (apart from sTfR). This is consistent with previous reports suggesting that the definition of iron deficiency is not universal and may need modification in some specific conditions [15].
Our study does not present the full picture of the interrelations between iron status, energy consumption, and outcome in HF. However, we believe that we have revealed a hint of a pathophysiological link between them. We assume that during each episode of AHF a patient is exposed to energetic stress. It remains unknown whether the elevation of lactate is a result of the inability to physiologically adapt to the stress (i.e. due to iron deficiency) or whether the lactate level is rather a marker of the magnitude of the stress (because every patient may be exposed to different magnitudes of the stressor). Most likely it is a combined effect of these two phenomena.

Unexpectedly, we found that patients with elevated lactate and STfR had some signs of worse clinical course of the disease (a trend towards longer hospital stay, higher furosemide and inotrope requirements), although this could not have been predicted using the baseline clinical and laboratory profiles. Furthermore, the poor response to therapy was not anticipated by the treating physicians because all groups received the same doses of diuretic within the first $24 \mathrm{~h}$ (Table 2).

Recently, we reported that AHF patients with unmet cellular iron requirements (sTfR) accompanied by depleted iron stores (hepcidin) represent a group with very unfavourable prognosis (mortality rate reaching 40\%) [16]. Moreover, we also demonstrated that elevated level of lactate in AHF patients without clinical signs of hypoperfusion is related to end-organ damage and high one-year mortality [8]. Our present analysis shows a different perspective on lactate and iron status in AHF pathophysiology because we have tried to reveal a link between functional intracellular iron insufficiency leading to energy debt and poor outcome.

There are several limitations to the presented analysis. The first and the most obvious one is a low number of examined patients and, therefore, a low number of events recorded during follow-up. Secondly, a serial assessment of lactate levels would probably be more adequate in identification of patients unable to cope with the stress related to AHF. Moreover, we have only provided data on lactate measured in capillary blood. Recently published studies showed a good correlation between lactate measured in capillary and arterial blood samples; however, one has to be cautious because the capillary blood may tend to reveal higher lactate values, especially in shock populations, which was not a case in our study [29-31]. In addition, the utility of hand-held devices for capillary lactate assessment in a population of patients after acute myocardial infarction has been shown [32]. Lastly, our hypothesis of energetic stress related to episodes of AHF needs to be further verified in future prospective studies.

Funding: The research was supported by a statutory grant to the Department of Heart Diseases, Wroclaw Medical University, Poland (No. ST-905, to P.P.).

Conflict of interest: Ewa A. Jankowska received personal fees for lectures from Viphor Pharma, and is a co-PI in the AFFIRME-AHF trial sponsored by Viphor Pharma. Other authors declare no conflict of interest. 


\section{References}

1. Weintraub NL, Collins SP, Pang PS, et al. Acute heart failure syndromes: emergency department presentation, treatment, and disposition: current approaches and future aims: a scientific statement from the American Heart Association. Circulation. 2010; 122(19): 1975-1996, doi: 10.1161/CIR.0b013e3181f9a223, indexed in Pubmed: 20937981.

2. Gheorghiade M, Pang PS. Acute heart failure syndromes. J Am Coll Cardiol. 2009; 53(7): 557-573, doi: 10.1016/j.jacc.2008.10.041, indexed in Pubmed: 19215829.

3. Hartupee J, Mann DL. Neurohormonal activation in heart failure with reduced ejection fraction. Nat Rev Cardiol. 2017; 14(1): 30-38, doi: 10.1038/nrcardio.2016.163, indexed in Pubmed: 27708278 .

4. Hillege H, Girbes A, de Kam PJ, et al. Renal function, neurohormonal activation, and survival in patients with chronic heart failure. Circulation. 2000; 102(2): 203-210, doi: 10.1161/01.cir.102.2.203.

5. Biegus J, Zymliński R, Sokolski M, et al. Liver function tests in patients with acute heart failure. Pol Arch Med Wewn. 2012; 122(10): 471-479, indexed in Pubmed: 23037318.

6. Biegus J, Zymliński R, Sokolski M, et al. Impaired hepato-renal function defined by the MELD XI score as prognosticator in acute heart failure. Eur J Heart Fail. 2016; 18(12): 1518-1521, doi: 10.1002/ejhf.644, indexed in Pubmed: 27709804.

7. Zymliński R, Sokolski M, Siwolowski P, et al. Elevated troponin I level assessed by a new high-sensitive assay and the risk of poor outcomes in patients with acute heart failure. Int J Cardiol. 2017; 230: 646-652, doi: 10.1016/j.ijcard.2017.01.012, indexed in Pubmed: 28069251.

8. Zymliński R, Biegus J, Sokolski M, et al. Increased blood lactate is prevalent and identifies poor prognosis in patients with acute heart failure without overt peripheral hypoperfusion. Eur J Heart Fail. 2018; 20(6): 1011-1018, doi: 10.1002/ejhf.1156, indexed in Pubmed: 29431284.

9. Andersen LW, Mackenhauer J, Roberts JC, et al. Etiology and therapeutic approach to elevated lactate levels. Mayo Clin Proc. 2013; 88(10): 1127-1140, doi: 10.1016/j.mayocp.2013.06.012, indexed in Pubmed: 24079682.

10. Ørn S, van Hall G. Does a normal peripheral lactate value always indicate an aerobic tissue metabolism? Eur J Heart Fail. 2017; 19(8): 1034-1035, doi: 10.1002/ejhf.863, indexed in Pubmed: 28547836.

11. Attanà $\mathrm{P}$, Lazzeri $\mathrm{C}$, Picariello $\mathrm{C}$, et al. Lactate and lactate clearance in acute cardiac care patients. Eur Heart J Acute Cardiovasc Care. 2012; 1(2): 115-121, doi: 10.1177/2048872612451168, indexed in Pubmed: 24062898.

12. Chertoff J, Chisum M, Garcia B, et al. Lactate kinetics in sepsis and septic shock: a review of the literature and rationale for further research. J Intensive Care. 2015; 3: 39, doi: 10.1186/s40560-0150105-4, indexed in Pubmed: 26445673.

13. Adamo L, Nassif ME, Novak E, et al. Prevalence of lactic acidaemia in patients with advanced heart failure and depressed cardiac output. Eur J Heart Fail. 2017; 19(8): 1027-1033, doi: 10.1002/ejhf.628, indexed in Pubmed: 27647751.

14. Harjola VP, Lassus J, Sionis A, et al. Clinical picture and risk prediction of short-term mortality in cardiogenic shock. Eur J Heart Fail. 2015; 17(5): 501-509, doi: 10.1002/ejhf.260.

15. Jankowska EA, von Haehling S, Anker SD, et al. Iron deficiency and heart failure: diagnostic dilemmas and therapeutic perspectives. Eur Heart J. 2013; 34(11): 816-829, doi: 10.1093/eurheartj/ehs224, indexed in Pubmed: 23100285.
16. Jankowska EA, Kasztura M, Sokolski M, et al. Iron deficiency defined as depleted iron stores accompanied by unmet cellular iron requirements identifies patients at the highest risk of death after an episode of acute heart failure. Eur Heart J. 2014; 35(36): 2468-2476, doi: 10.1093/eurheartj/ehu235, indexed in Pubmed: 24927731.

17. McMurray JJV, Adamopoulos S, Anker SD, et al. ESC guidelines for the diagnosis and treatment of acute and chronic heart failure 2012: The Task Force for the Diagnosis and Treatment of Acute and Chronic Heart Failure 2012 of the European Society of Cardiology. Developed in collaboration with the Heart Failure Association (HFA) of the ESC. Eur J Heart Fail. 2012; 14(8): 803-869, doi: 10.1093/eurjhf/hfs105, indexed in Pubmed: 22828712.

18. Dickstein K, Cohen-Solal A, Filippatos G, et al. ESC Guidelines for the diagnosis and treatment of acute and chronic heart failure 2008: the Task Force for the Diagnosis and Treatment of Acute and Chronic Heart Failure 2008 of the European Society of Cardiology. Developed in collaboration with the Heart Failure Association of the ESC (HFA) and endorsed by the European Society of Intensive Care Medicine (ESICM). Eur Heart J. 2008; 29(19): 2388-2442, doi: 10.1093/eurheartj/ehn309, indexed in Pubmed: 18799522.

19. Ponikowski P, Voors A, Anker S, et al. 2016 ESC Guidelines for the diagnosis and treatment of acute and chronic heart failure. Eur J Heart Fail. 2016; 18(8): 891-975, doi: 10.1002/ejhf.592.

20. Biegus J, Zymliński R, Sokolski M, et al. Clinical, respiratory, haemodynamic and metabolic determinants of lactate in heart failure. Kardiol Pol. 2019; 77(1): 47-52, doi: 10.5603/KP.a2018.0240, indexed in Pubmed: 30566223.

21. Kubiak GM, Tomasik AR, Bartus K, et al. Lactate in cardiogenic shock - current understanding and clinical implications. J Physiol Pharmacol. 2018; 69(1): 15-21, doi: 10.26402/jpp.2018.1.02, indexed in Pubmed: 29769417.

22. Garcia-Alvarez M, Marik P, Bellomo R. Stress hyperlactataemia: present understanding and controversy. Lancet Diabetes Endocrinol. 2014; 2(4): 339-347, doi: 10.1016/S2213-8587(13)70154-2, indexed in Pubmed: 24703052.

23. Nalos M, Leverve X, Huang S, et al. Half-molar sodium lactate infusion improves cardiac performance in acute heart failure: a pilot randomised controlled clinical trial. Crit Care. 2014; 18(2): R48, doi: 10.1186/cc13793, indexed in Pubmed: 24666826.

24. Lopaschuk GD, Ussher JR, Folmes CDL, et al. Myocardial fatty acid metabolism in health and disease. Physiol Rev. 2010; 90(1): 207-258, doi: 10.1152/physrev.00015.2009, indexed in Pubmed: 20086077 .

25. Johnson ML, Emhoff CA, Horning MA, et al. Transpulmonary lactate shuttle. Am J Physiol Regul Integr Comp Physiol. 2012; 302(1): R143-R149, doi: 10.1152/ajpregu.00402.2011, indexed in Pubmed: 22031785.

26. Biegus J, Zymliński R, Szachniewicz J, et al. Clinical characteristics and predictors of in-hospital mortality in 270 consecutive patients hospitalised due to acute heart failure in a single cardiology centre during one year. Kardiol Pol. 2011; 69(10): 997-1005, indexed in Pubmed: 22006596.

27. Kapłon-Cieślicka A, Drożdż J, Filipiak KJ. Prognostic factors in heart failure - are they all equally important? Kardiol Pol. 2017; 75(6): 519-526, doi: 10.5603/KP.a2017.0088, indexed in Pubmed: 28553872.

28. Ostrowska M, Ostrowski A, Łuczak M, et al. Basic laboratory parameters as predictors of in-hospital death in patients with acute decompensated heart failure: data from 
a large single-centre cohort. Kardiol Pol. 2017; 75(2): 157-163, doi: 10.5603/KP.a2016.0147, indexed in Pubmed: 27714721.

29. Collange O, Garcia V, Kindo M, et al. Comparison of capillary and arterial lactate levels in patients with shock. Anaesth Crit Care Pain Med. 2017; 36(3): 157-162, doi: 10.1016/j.accpm.2016.08.007, indexed in Pubmed: 27867135.

30. Dépret F, Legrand M. Are capillary and arterial lactates interchangeable? Anaesth Crit Care Pain Med. 2017; 36(3): 149, doi: 10.1016/j.accpm.2017.04.001, indexed in Pubmed: 28647080.
31. Sabat J, Gould S, Gillego E, et al. The use of finger-stick blood to assess lactate in critically ill surgical patients. Ann Med Surg (Lond). 2016; 10: 41-48, doi: 10.1016/j.amsu.2016.07.021, indexed in Pubmed: 27547397.

32. Kubiak GM, Jacheć W, Wojciechowska C, et al. Handheld capillary blood lactate analyzer as an accessible and cost-effective prognostic tool for the assessment of death and heart failure occurrence during long-term follow-up. Dis Markers. 2016; 2016: 5965782, doi: 10.1155/2016/5965782, indexed in Pubmed: 28115788.

Cite this article as: Biegus J, Zymliński R, Sokolski M, et al. Elevated lactate in acute heart failure patients with intracellular iron deficiency as an identifier of poor outcome. Kardiol Pol. 2019; 77(3): 347-354, doi: 10.5603/KP.a2019.0014.

\section{WHAT IS NEW?}

We believe that there is a physiological link between intracellular iron status and efficiency of energy production/consumption (assessed by lactate, a product of anaerobic cell metabolism), which may further impact the outcome of patients with acute heart failure (AHF). During each AHF episode patients are exposed to metabolic stress, and those unable to cope with the stress may have a worse outcome. We aimed to examine if elevated lactate levels $(>2 \mathrm{mmol} / \mathrm{L}$ ) accompanied by unmet cellular iron requirements (defined as the elevation of soluble transferrin receptor $>1.59 \mathrm{mg} / \mathrm{L}$ ) on admission identify patients with an unfavourable outcome. We have shown that coexistence of iron deficiency and elevated lactate is very common among patients with $\mathrm{AHF}$, occurring in approximately $40 \%$ of cases. Moreover, for the first time, we have shown that a group of patients with hyperlactataemia and elevated soluble transferrin receptor on admission have significantly higher mortality risk when compared to individuals without those pathologies. It is possible that iron supplementation in AHF may promote more efficient energy production pathways, but this needs to be prospectively examined. 